\title{
INDICATOR SYSTEMS FOR MUNICIPAL SUSTAINABLE DEVELOPMENT GOVERNANCE: PREREQUISITES FOR DESIGN AND IMPLEMENTATION
}

\author{
JANIS KAULINS, RAIMONDS ERNSTEINS \& IVARS KUDRENICKIS \\ University of Latvia, Latvia
}

\begin{abstract}
The theoretical basis of indicator system (IS) elaboration for sustainable development governance (SDG) has been step-wise developing, but is still insufficiently linked with both the theory and especially the practice of municipal governance system and process. The research has been completed about SDG IS elaboration, design and construction for the governance process of municipal territorial development. The set of complementary prerequisites for building IS has been established, including further development of the key concepts for the integrativity of SDG indicators, relationships between sustainability dimensions (particularly including governance and communication dimension), and horizontal and vertical integration approaches. Concepts have been tested and applied, including a full-scale application of SDG IS at the Saulkrasti local municipality in Latvia, while a Sustainable Development Strategy, as the mandatory long-term planning document, was elaborated within related municipal participatory process. Theoretical and practical recommendations have been produced and disseminated. Demo examples of testing various thematic IS and legal full-scale implementation of the first municipal practice case of SDG IS in Latvia has attracted interest, even though such IS implementation requires complex and sizeable resources.
\end{abstract}

Keywords: municipal indicator system, construction, horizontal integration, vertical integration.

\section{INTRODUCTION}

It should be formally recognized that, initially, indicator systems (IS) for sustainable development governance (SDG) had been developing step-wise, initially on the basis of environmental indicators, later adding other dimensions and environmental, social and economic dimensions, and gradually becoming more evenly balanced and more often supplemented, as definitely importantly, by the fourth dimension - the governance dimension [1]-[4]. The United Nation Food and Agricultural Organization has been giving important contribution for practically applicable IS by producing theoretical outlines and practice conclusions [5]. Traditionally, IS formation models were based upon functional analysis of system to be researched [6], [7] or the problem analysis of the territory [8], but not often were linked with the governance of the territory and the content of the mandatory development planning documents, e.g. process of making governance decisions. Indicators, being the main informative assessment and communication instrument for the SDG, have lately become increasingly important in the process of elaboration and assessment of documents. Nowadays the government, but also more and more the municipal planning and different cross-sectorial planning (coast, agglomerations, sectors, etc.) are demanding much better elaborated principles for IS formation, information basis for provision of it and recommendations for the usage and appropriate sustainable decision making.

The general objective of the research performed was to study and to design the set of prerequisites for the building of SDG IS, their content and process structure and complementary composition in order to be used for municipal development governance supervision process as well as to produce, approve and test local level IS for selected coastal municipality (Saulkrasti case), looking also ahead towards linking that local IS hierarchically and structurally with the IS of higher administrative governance levels. As the result of the 
research, theoretically based and flexibly applicable, various management instruments had to be generated, allowing to produce and use indicators of SDG and their systems for supervision of middle and long term sustainable development planning documents as nowadays requested from municipalities for the purposes of territorial governance of different levels and functions.

There were internationally and especially locally taking place the necessary developments of the understanding about structure and construction of SDG IS as such, since having some initial list of parameters this is not yet ready IS, having structured, logical and deliberated reciprocal commitments. Especially important is the integration principle application for to be developed IS, reflecting links between elements of sustainability dimensions both in the municipal practice and/or between one sector planning document and other sector planning documents at the same governance level (horizontal integration) and between other governance levels (vertical integration). Finding of such links at indicator level is described [9] and at planning formulation level also [10], however the majority of IS construction research is devoted to the problem of some very practical aspects [1], [2], [11] or applied studies without theoretical generalizations on IS as systems [2], [8], [12]-[14].

\section{SCOPE AND METHODS}

When planning the realization of the research purpose formulated, there is necessary to scope all appropriate theoretical understandings and particular approaches accordingly to the general situation problem analysis as mentioned above, select related set of complementary research methods representing both academic and applied studies, and, elaborate step-wise research and development (R\&D) process in order to construct and test initially the separate SDG indicators understanding/formulation and application in the governance process as well ongoing work with various IS applications. Working with design and construction of IS being necessarily to be adapted on national and regional/local (municipal) governance levels, it should be recognized and taken as overall approach for R\&D work, that municipal IS building requires both - complementary integration of the indicators itself as well as the whole IS into development governance process and development planning documentation, to be finally legally approved by municipal Council (incl. at least formal public participation process) and later on implemented. Subsequently, R\&D study was also subdivided into all related complementary parts: designing approach and principles; IS structure understanding and building; construction of IS at the planning process and content application/information; integration - horizontally and vertically as well as within stakeholder process mutually; and finally - all parts altogether at full scale testing as SDG IS for Saulkrasti municipality.

The following main groups of research methods were complementary used: (1) case study research (CSR), which implies acquisition of thematically coordinated information during the field studies [15] using the analysis of socio-economic and natural environment data, e.g. document studies, field observations, interviews with target group representatives and focus groups inquiries (not all methods must be included for particular specific study); (2) approbation research, using all various possibilities of testing R\&D results; (3) expert interviews beyond the CSR frame.

The CSR was mainly applied in five research studies carried out within the framework of the development planning works of municipal territorial development (Aglona, Beverīna, Cesvaine, Salacgrīva and Saulkrasti municipalities in Latvia). The research begins with complex analysis of natural environment, socio-economic environment and their interaction data as for socio-ecological systems and their governance process and institutionalstakeholders' constellation that allows to obtain initial overview of different types of resources of the territory and to form the informational basis for the further procedure of the 
research. Likewise, information sources and types were also explored that would be possible to use later on in application of IS for SDG. Most important are the semi-structured and deep interviews with the representatives of all main target groups: (1) municipal governance (all three main employment layers - councilors, management and also auxiliary service organizations and institutions) and complementary (2) general public representations, (3) local/regional corporate sector; (4) national governance representations at the local/regional level; and (5) all mediators (incl. NGO's, media, education (formal and esp. non- and in-formal), science/technology representatives). Each CSR case included 30-50 stakeholder interviews and at least 1-2 focus groups. Regarding the IS, the common goals of CSR for all cases were two: (1) "unsorted" list of parameters, that are candidates for use as SDG indicators and (2) eventual structure of the future IS, including priority integrated problem areas, dimensions of sustainability and links with related IS, if such exist.

The expert interviews (altogether 15) were complementary with local CSR and mostly useful for establishing of an IS structure by priority integrated problem areas, identifying leading and strategic (or integral) indicators, extracting non-applicable parameters. The interviews included also information about the aspects of integrated planning and indicator usage in elaboration of municipal development planning documents.

Three types of approbations can be distinguished among the methods: in seminars of practical research, in the planning process and final approbation. The final approbation at the Saulkrasti municipality - indicators were used both for information acquisition and structuring in the planning process and as a part of supervision of sustainable development strategy. IS for SDG was implemented in three phases. First of all, the indicator list was specified and elaborated based on the results of research carried out during the planning process. After that, the manual of IS was produced, consisting of system's description, instructions for the result reflection, all indicator statements, detailed data acquisition and calculation methodologies and samples of how to demand information from related institutions. The training of the personnel of the municipality also took place within the process of implementation.

\section{RESULTS AND DISCUSSION}

IS development studies described above has been planned-organized-realized as R\&D program: (1) as mutually complementary four components for IS development - designing approach and structure building, construction and integration as well as (2) full scale testing and legal application of SDG IS for Saulkrasti municipality. In the meantime, also various other thematic municipal IS, e.g. for climate change adaptation governance, coastal risks governance, healthy and environmental-friendly food governance, has been tested for further developments and full scale future applications, but being not discussed in this paper.

\subsection{Indicator systems: design}

In order to ensure the process of sustainable development governance (problem analysis, policy formulation, planning, supervision and evaluation) several basic principles must be observed, which characterize the development process of IS and separate indicators within the structure of these systems. First of all, IS development is to be mandatory and mutually linked with all governance process steps/stages and not only with supervision and evaluation stage. The indicator informative provision and domain, the integrativity of indicator and horizontal and vertical integration of the IS form the complementary set of prerequisites for SDG IS development that allow to make the IS for the needs of specific territories and issues/branches. This is IS design frame. 
Informative support of indicator is to be described as the conditions at which the selected factor from the list of feasible factor group becomes the real functioning indicator, the readings of which for particular indicators and their systems on the whole are the basis for the governance decision making in the process of territorial development planning and supervision. The interconnectedness of indicators is determined by indicator integration, which characterizes the relationships of certain indicators with sustainability dimensions and their interaction areas that allow formation of balanced IS for sustainable development planning, supervision and assessment. IS are to be characterized by horizontal integration, ensuring the compliance with interconnectedness of sustainability dimensions and integrative problem areas, allowing adequately and complementary reflect sustainability dimensions, its branch integrity and distribution of common and specific factors. IS are to be characterized also by vertical integration, allowing forming harmonic meta-system from different levels of indicators and understanding its condition of SDG, progress and contribution within the context of the whole sustainable development in all of the governance levels.

\subsection{Indicator systems: content structure}

Studies of a number of different IS illustrate, that, regardless of the appliance field of system, the basic principles of their construction are similar: structured by reflected themes and hierarchic by levels of information generalization (Fig. 1). All the levels and elements specified here may not be for any IS present. For example, IS for assessment of coastal sustainability DEDUCE [13] does not contain strategic indicators; it is a characteristic for areas without united, common governance.

While, national scale IS [15], [17]-[21], including strategy "Latvija-2030" [4], oriented on using of statistics, one parameter indicators are dominated, i.e., value of indicator is the same value, obtained from a data source. One-level grouping is typical for IS, which are not linked directly with some planning document, for example, national system of sustainable development indicators in Latvia [22].

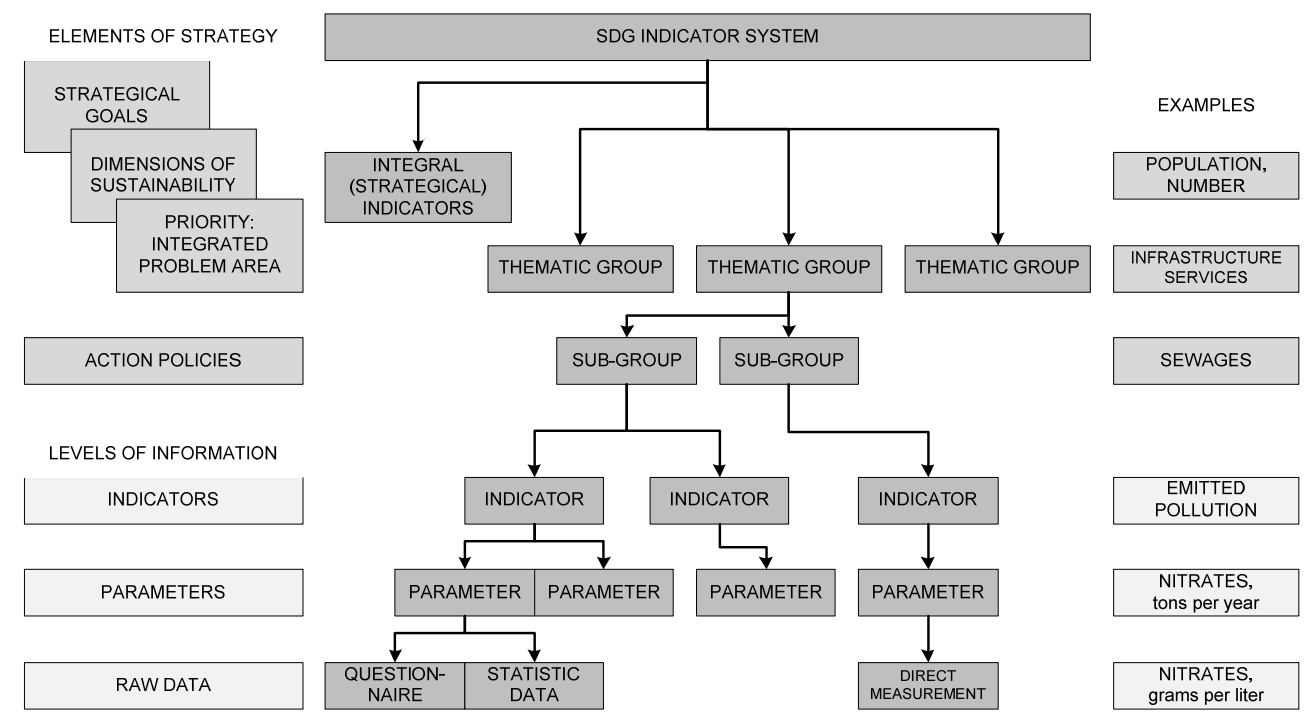

Figure 1: Hierarchical structure of SDG indicator system [16]. 


\subsection{Indicator systems: construction}

The studies of great number of different IS reveal that, irrespective of the type of IS, they all have in common structured and hierarchical design. Indicators are divided into thematic groups within the system that are formed according to sustainable dimensions or of prior integrative problem principle. These groups include subgroups which, in turn, are formed according to the branch or course of action principle. Indicators that are subgroups may consist of one or several measurable parameters, but for determination of each parameter one or several value measurements might be necessary.

The indicator selection is associated with selection of definite characteristic value of the branch or course of action. It is done, first of all, according to specific algorithm, examining the relationship of these values with sustainability, governance and afterwards checking the conformity of the selected values to the informative provision of chosen prerequisites. The selection of potential indicators for possible strategic goals, prior integrative problems and the characteristic parameters of integrated planning process related to long term courses of action are shown in Fig. 2. During this selection process, the verification is done to clarify

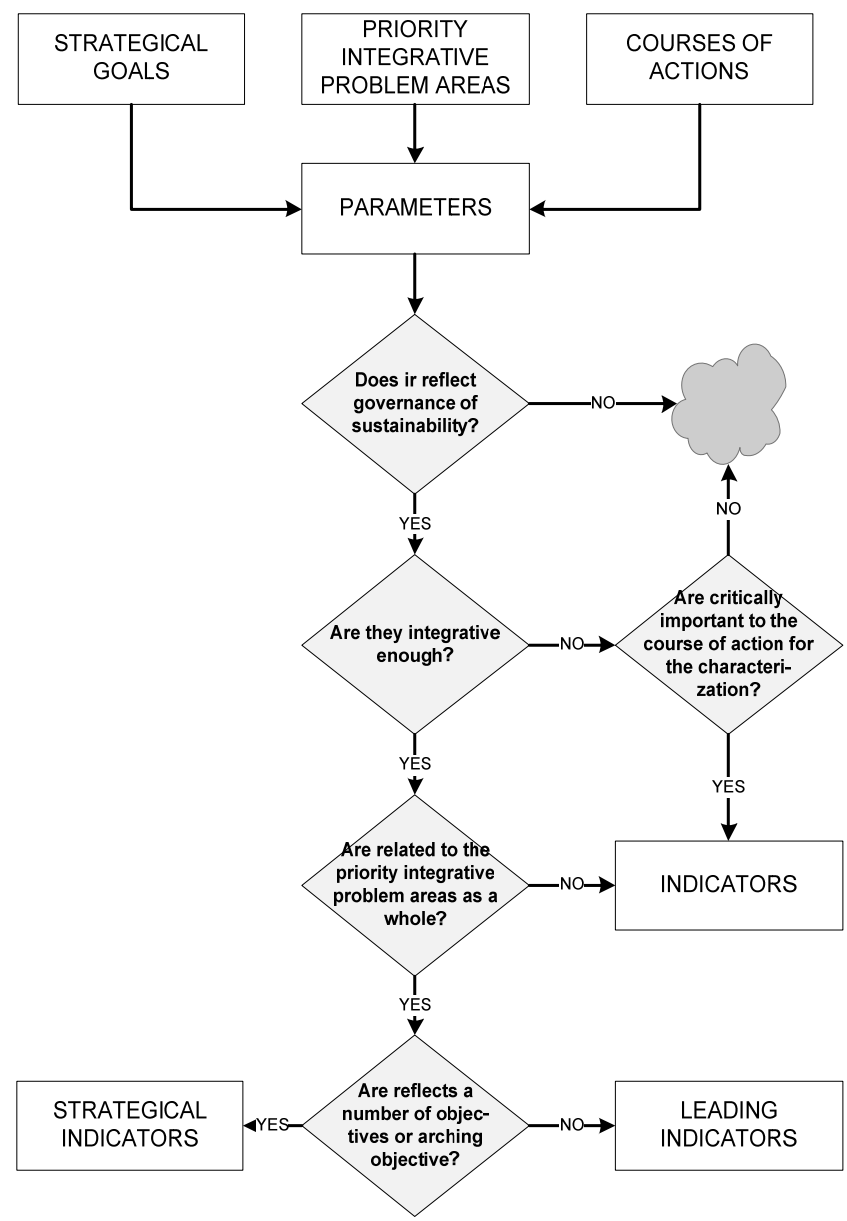

Figure 2: Selection of indicators at planning process [23]. 
if the indicator meets the requirements of indicator for the SDG, i.e., if there is a connection with the main aspects of sustainability, governance, as well as assessment of integrity of the indicator. Finally, the proposed indicators are arranged, singling out leading and strategic (integral) indicators.

The verification of the selected potential indicators to comply with the set of prerequisites for informative provision of indicator and domain of governance indicator is represented in Fig. 3. During the selection process the significance of those parameters that formally are not included in domain of indicator for SDG is also assessed, which can be for some reason sufficiently significant in governance decision making.

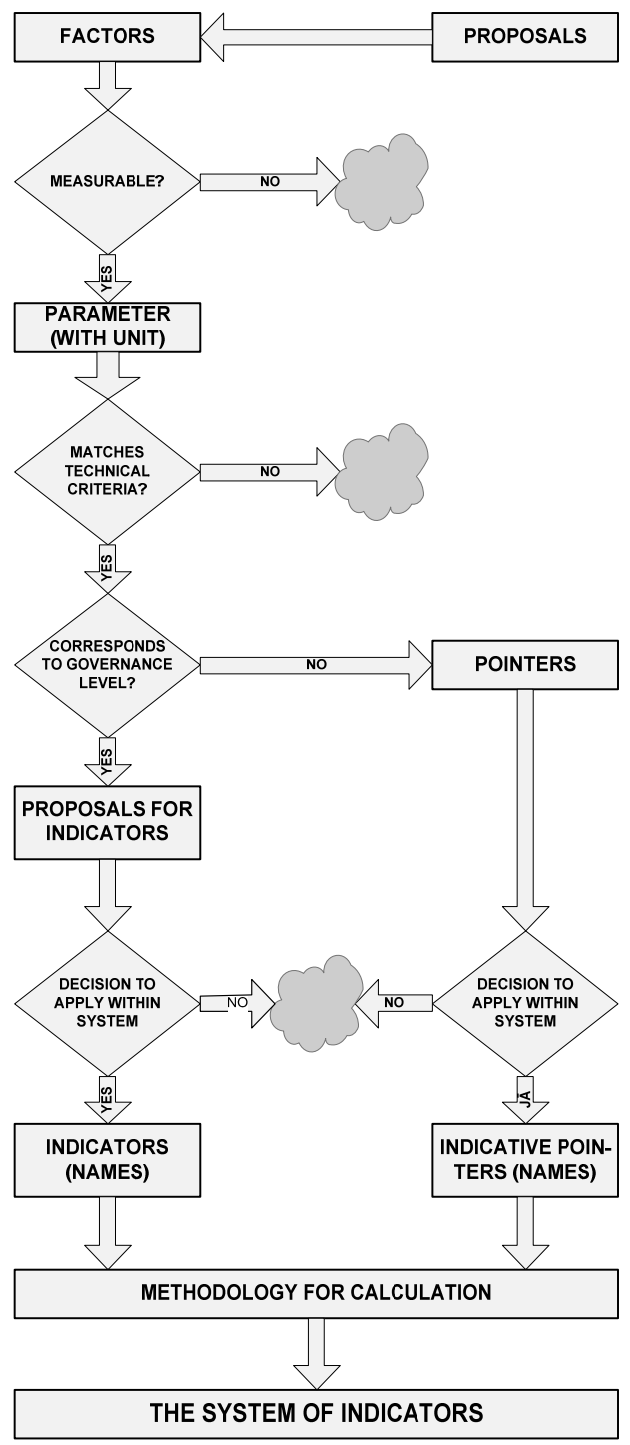

Figure 3: Selection of indicators by the set of prerequisites for informative provision of indicator [24]. 


\subsection{Indicator systems: integration}

The vertical integration principle means the relationship of indicator system with IS which is effective in other governance levels and it is necessary for mutual comparability of different territories, as well as for the clarification of common tendencies. Three-level vertical integration must be observed in municipal model (Fig. 4): at least part of the main parameters, related to the strategic goals, must be associated with governance indicators and on the whole, with non-existent for the moment regional level indicators. Territory is characterized not only per administrative-territorial division, but also via areas of special significance, which can be indirectly associated with administrative division. National SD Strategy "Latvia-2030" [4] prescribes several of such territories that are areas of national interest, e.g. coastal territories. Principle of vertical integration, declared here for IS in Latvia, now is at further studies and elaboration processes. The main tasks for vertical integration is to find a suitable representation from higher level governance indicators at lower level of governance and to find the right proportions for different components of the system.

There is also an example of the realization of horizontal integration principle in formation of IS in governance practice of local municipality (Table 1). This indicator system has been elaborated for the Salacgrivva municipality in the course of planning of sustainable development strategy. System is characterized by horizontal integrity as it was evaluated among problem fields and sustainable development trends, consequently transferring this relationship to the indicators, which describe particular fields. System contains 16 integral (strategic) indicators, referring on various aspects of ultimate targets for the strategy and 64 indicators, referring to all defined long-term action policies and groups of tasks.

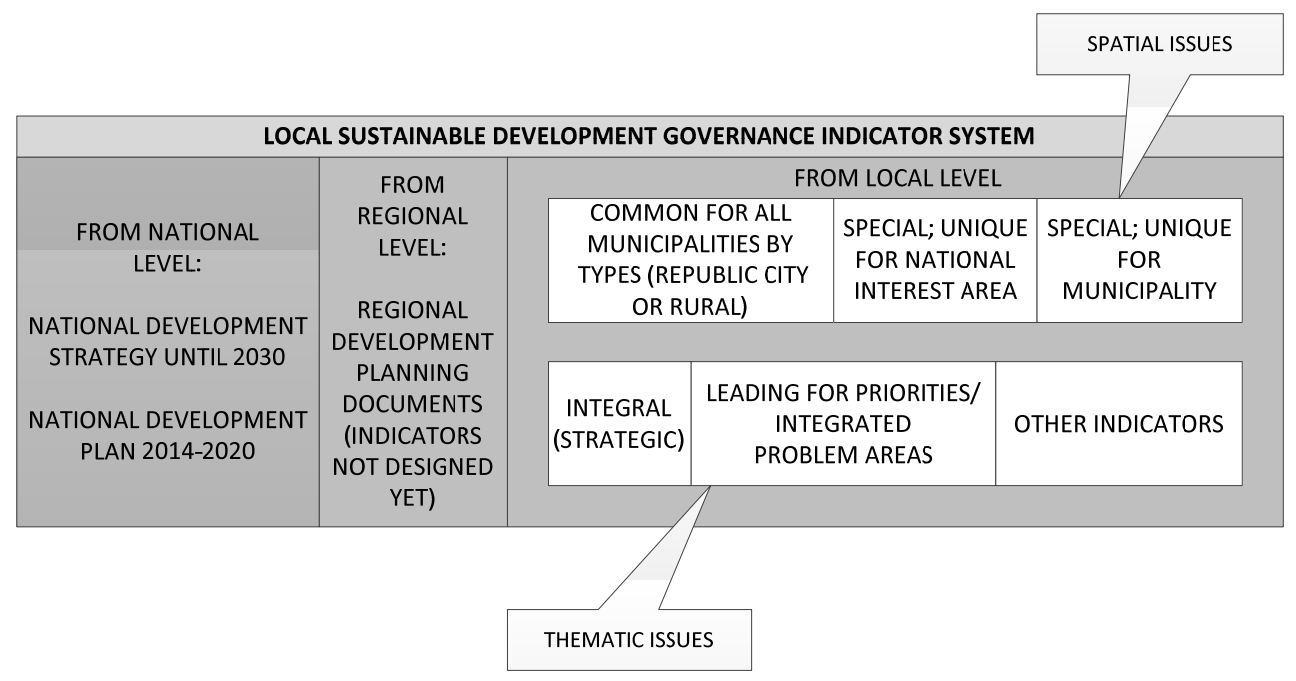

Figure 4: The principle of vertical integration for municipal SDG indicator system [23]. 
Table 1: Example cross-interactions between municipal policy fields - realization of horizontal integration principle in formation of IS in Salacgriva municipality.

\begin{tabular}{|c|l|c|c|c|c|c|c|c|c|c|c|c|c|}
\hline Nr. & Policy development fields & 1.1. & 1.2 & 2.1 & 2.2. & 2.3. & 3.1 & 3.2 & 3.3 & 4.1. & 4.2. & 5.1. & 5.2. \\
\hline 1.1. & $\begin{array}{l}\text { Social environment and quality } \\
\text { of services }\end{array}$ & & $\mathbf{x}$ & & $\mathbf{x}$ & & $\mathbf{X}$ & $\mathbf{x}$ & $\mathbf{x}$ & $\mathbf{x}$ & $\mathbf{X}$ & & $\mathbf{x}$ \\
\hline 1.2. & $\begin{array}{l}\text { Professional knowledge and self- } \\
\text { development of society }\end{array}$ & $\mathbf{x}$ & & $\mathbf{X}$ & & $\mathbf{x}$ & & $\mathbf{x}$ & $\mathbf{x}$ & & $\mathbf{x}$ & $\mathbf{x}$ & \\
\hline 2.1. & $\begin{array}{l}\text { General business } \\
\text { competitiveness }\end{array}$ & & $\mathbf{X}$ & & $\mathbf{X}$ & $\mathbf{X}$ & $\mathbf{X}$ & $\mathbf{x}$ & $\mathbf{X}$ & & $\mathbf{x}$ & $\mathbf{X}$ & \\
\hline 2.2. & Environment-friendly food cycle & $\mathbf{x}$ & & $\mathbf{X}$ & & $\mathbf{X}$ & & & & $\mathbf{x}$ & $\mathbf{x}$ & $\mathbf{X}$ & $\mathbf{X}$ \\
\hline 2.3. & $\begin{array}{l}\text { Tourism information, paths and } \\
\text { targets }\end{array}$ & & $\mathbf{x}$ & $\mathbf{X}$ & $\mathbf{X}$ & & $\mathbf{X}$ & $\mathbf{X}$ & $\mathbf{X}$ & & & $\mathbf{x}$ & \\
\hline 3.1. & Traffic services and organization & $\mathbf{X}$ & & $\mathbf{X}$ & & $\mathbf{X}$ & & $\mathbf{X}$ & $\mathbf{X}$ & $\mathbf{x}$ & $\mathbf{x}$ & $\mathbf{x}$ & \\
\hline 3.2. & Coastal infrastructure & $\mathbf{x}$ & $\mathbf{x}$ & $\mathbf{x}$ & & $\mathbf{X}$ & $\mathbf{X}$ & & $\mathbf{x}$ & & & $\mathbf{X}$ & \\
\hline 3.3. & Port development & $\mathbf{x}$ & $\mathbf{x}$ & $\mathbf{X}$ & & $\mathbf{X}$ & $\mathbf{X}$ & $\mathbf{x}$ & & & & $\mathbf{x}$ & \\
\hline 4.1. & $\begin{array}{l}\text { Collaborative governance for } \\
\text { nature values }\end{array}$ & $\mathbf{x}$ & & & $\mathbf{x}$ & & $\mathbf{x}$ & & & & & & $\mathbf{X}$ \\
\hline 4.2. & $\begin{array}{l}\text { Adaptation to climate changes } \\
\text { and nature risk factor mitigation }\end{array}$ & $\mathbf{X}$ & $\mathbf{x}$ & $\mathbf{x}$ & $\mathbf{x}$ & & $\mathbf{x}$ & & & & & & $\mathbf{x}$ \\
\hline 5.1. & $\begin{array}{l}\text { Image of municipality and brand } \\
\text { substantive policy }\end{array}$ & & $\mathbf{x}$ & $\mathbf{X}$ & $\mathbf{X}$ & $\mathbf{x}$ & $\mathbf{x}$ & $\mathbf{X}$ & $\mathbf{x}$ & & & & $\mathbf{X}$ \\
\hline 5.2. & Public environmental awareness & $\mathbf{x}$ & & & $\mathbf{X}$ & & & & & $\mathbf{X}$ & $\mathbf{x}$ & $\mathbf{X}$ & \\
\hline
\end{tabular}

$\mathrm{X}$ : close relationship; $\mathrm{x}$ : detectable relationship.

\subsection{SDG indicator systems: Saulkrasti municipality success story}

In the 2013 the fully functioning IS for the SDG, as for the first time in Latvia, has been produced and legally implemented in the Saulkrasti coastal municipality after decision of local municipal council, being assigned as direct supervision instrument for the SD Strategy implementation progress and for the usage in the governance practice of the local management level. The IS has been elaborated based upon theoretical conclusions arising from the research on integrated development planning and the significance and position of necessary indicators. IS for SDG is incorporated into sustainable development strategy as the informative basis of nowadays mandatory supervision process/requirements and assessment mechanism.

SDG IS consists of the structured list of indicators, grouped into four sustainability dimensions and integrative problem fields, revised in 2017 (66 indicators; generalized overview of their groupings shown in Table 2). The main practical document for usage of the system is the manual, containing general instructions, methodological recommendations for each of individual indicator, instruction about data processing and representation for the needs of decision makers and other public target groups are provided. During the system's implementation the training of the municipality's personnel was organized on practical implementation and usage of IS. The IS has been approved for the practical use by the resolution of municipal Council, being as a complementary part of the municipal sustainable development strategy document. 
Table 2: $\quad$ Saulkrasti municipality sustainable development governance indicator system content list of indicators grouped by four sustainability dimensions and related thematic groups; [26], revised).

\begin{tabular}{|l|l|}
\hline \multicolumn{2}{|c|}{ Integral (strategic) indicators (I) } \\
\hline \multicolumn{2}{|c|}{ I1. Demography (2*); I2. General indices (3) } \\
\hline \multicolumn{1}{|c|}{ Nature environment (D) } & \multicolumn{1}{|c|}{ Economic environment (E) } \\
\hline D1. Nature; biodiversity (3) & E1. Labour force and it's reserve (2) \\
D2. Household impacts (4) & E2. Budget, finances of municipality (2) \\
D3. Air quality and impact on climate change (2) & E3. Entrepreneurship (3) \\
D4. Sea and surface water quality (2) & E4. Mobility (4) \\
D5. Land resources, construction (2) & E5. Energy sources (1) \\
D6. Coast as a resource (1) & E6. Tourism characteristics (7) \\
D7. Common indications (1) & E7. Commercial services (2) \\
\hline \multicolumn{1}{|c|}{ Social environment (S) } & \multicolumn{1}{|c|}{ Governance and communication (P) } \\
\hline S1. Healthcare characteristics (4) & P1. Municipal governance (2) \\
S2. Culture, sports (3) & P2. Municipal communication (3) \\
S3. Social and physical safety (4) & P3. Activities in non-governmental \\
S4. Education (5) & sector (2) \\
S5. Household life quality (2) & \\
\hline
\end{tabular}

*Number of indicators within each of the thematic groups is mentioned in the brackets and total number of indicators is 66 .

During 2014-2015, as for every two-year period of SD Strategy realization, the first full-scale assessment of SDG has been provided as all indicators were calculated within framework of the Latvian National Research Program Project SUSTINNO. As for R\&D approach there is started also new policy initiative, involving all main stakeholders - the work on Municipal Sustainability Report 2015 is in the process now as the first of this kind of SD evaluation processes and related documents in Latvia. A similar approach is used in practice [25], but it is based on only a limited use of indicators.

\section{CONCLUSIONS}

1. Analysis of governance practices at the local municipal level has identified that there is still a lack of appropriate instruments to govern the development process. IS can effectively contribute to closing this gap and thus shall be developed and used as the instrument for municipal SDG and the elaboration of related policy initiatives. Thus, IS as the governance instrument shall have both applications: it has to be employed already during the process of elaboration of the sustainable development strategy as well as during the process of progress assessment.

2. The pilot study carried out in the coastal Saulkrasti municipality, resulted in the elaboration the fully functioning IS for SDG. This was the first time a system like this was developed in local municipality in Latvia. Development of this IS revealed the overall design, construction, content, structure and process (incl. integration) requirements for elaboration of similar IS at municipal level.

3. The precondition for successful application of IS are a clear definition and subsequently - a perfect understanding of the place of IS in the municipal planning system by all the stakeholders. Namely, IS shall be developed and approved as a part of municipal planning system and included in mandatory in Latvia Municipal Sustainable Development Strategy.

4. In order for IS to become a useful instrument for municipal SDG several prerequisites should be met: information necessary for calculation of the indicators has to be available; 
indicators domain shall be established, indicators have to build up an internally integrated system; there should be horizontal and vertical integration within/outside the IS. Meeting these preconditions would allow to develop an adequate and development content/process representative IS for either general or specific needs of any given territory or given field.

5. The key user of IS are the municipality. The capacity building of IS users (particularly, the staff of municipality administration) is mandatory requirement for success of IS application. The pilot study allowed our team to create a list of supplementary documents (for example, IS application manual, methodological recommendations for using the IS) necessary to help municipalities to become an independent (from external consultation needs) users of the IS. We also indicated the necessity for development of the public based monitoring system as part of eventual general municipal monitoring, also monitoring instruments for SDG. Rising public awareness of SDG is, therefore, an important precondition for introducing such monitoring system.

6. Supervision, monitoring and assessment of implementation of the Sustainable Development Strategy should be based on the data acquired through IS. After full measurement and calculation process of each indicator and all sub-systems of IS, the first Municipal Sustainability Progress Report, is currently elaborated by our research team for Saulkrasti Municipality.

7. Further research on both horizontal and also vertical integration for IS, esp. specifying the proportions of integrated components into IS for SDG at the different governance levels, is to be conducted, as well as approbation of horizontal/vertical integration on the regional IS level and more detailed linkage with national level, since looking towards coordinated indicator system, covering all levels and sectors.

\section{ACKNOWLEDGEMENTS}

R\&D data were collected and elaborated upon, and the paper prepared, within the framework of the Latvian National Research Program Project on Environmental Diversity and Sustainable Governance (SUSTINNO, 2014-2017). There shall be acknowledged following university contributors taken part into the realization of previous CSR projects mentioned Ivars Kudrenickis, Ilga Zilniece, Anita Lontone, Liga Zvirbule, Valdis Antons, Diana Sulga, Sintija Kursinska, Daiga Stelmahere as well as master students involved and contributed municipal leaders, planners and other stakeholders from CSR pilot areas.

\section{REFERENCES}

[1] Ernsteins, R., Kaulins, J., Zilniece, I. \& Lontone, A., Coastal governance solutions development in latvia: collaboration communication and indicator systems. Coastal Zones, Chapter 6, Elsevier (in print), 2015.

[2] Moreno-Pires, S. \& Fidélis, T., A proposal to explore the role of sustainability indicators in local governance contexts: The case of Palmela, Portugal. Ecological Indicators, 23, pp. 608-615, 2012.

[3] Rydin, Y. \& Holman, N., Local sustainability indicators. Local Environment, 8(6), pp. 581-589, 2003.

[4] Sustainable development strategy of Latvia Republic until 2030. Ministry of Environment and Regional development, Riga, 100 pp., 2010.

[5] Brown, J. \& Reyntjens, D., INDECO: Indicators - an overview internal paper for discussion, 2005.

[6] Becker, J., Measuring progress towards sustainable development: an ecological framework for selecting indicators. Local Environment, 10(1), pp. 87-101, 2005. 
[7] Bossel, H., Assessing viability and sustainability: a systems-based approach for deriving comprehensive indicator sets. Conservation Ecology, 5, p. 12, 2001.

[8] Scipioni, A., Mazzi, A. \& Mason, M., The dashboard of sustainability to measure the local urban sustainable development: the case study of Padua Municipality. Ecological Indicators, 9, pp. 364-380, 2009.

[9] Saulkrasti Municipality: strategy of sustainable development for 25-year perspective. Saulkrasti district, KBLC Ltd., 90 pp., 2013. Unpublished (in Latvian).

[10] Sano, M. \& Medina, R., A systems approach to identify sets of indicators: Applications to coastal management. Ecological Indicators, 23, pp. 588-596, 2012.

[11] Moldan, B., Janoušková, S. \& Hák, T., How to understand and measure environmental sustainability: Indicators and targets. Ecological Indicators, 17, pp. 4-13, 2012.

[12] Marti, X. \& Lescrauvaet, A-K., Indicators guidelines: To adopt an indicators-based approach to evaluate coastal sustainable development. DEDUCE Consortium, Interreg IIIc, Barcelona, 98 pp., 2007.

[13] Saulkrasti Municipality: strategy of sustainable development for 25-year perspective. Manual for using sustainable development governance indicator system. KBLC Ltd.: 160 pp., 2013, unpublished (in Latvian).

[14] Sustainable development indicators in Hungary, Central Statistical Office. Budapest, 299 pp., 2011.

[15] Yin, R.K., Case Study Research: Design and Methods, 2nd ed., SAGE Publications, Inc., 172 pp., 1994.

[16] Kauliņš, J., Ernšteins, R. \& Kudreņickis, I., Sustainable development indicators for integrated coastal management: definition area and spatial properties. WIT transaction to Ecology and the Environment, 144, pp. 299-311, 2011.

[17] Denmark's National Strategy for Sustainable Development: Shared future - balanced development. Indicator report. The Danish government, August, 100 pp., 2002.

[18] Ghosh, S., Vale, R. \& Vale, B., Indications from Sustainability Indicators. Journal of Urban Design, 11(2), pp. 263-275, 2006.

[19] Indicators of sustainable development, Eesti statistika, Tallinn, 164 pp., 2011.

[20] Mader, C., Sustainability process assessment on transformative potentials: The Graz Model for Integrative Development. Journal of Cleaner Production, 49, pp. 54-63, 2013.

[21] Suvorov, M., Rutar, T. \& Žitnik, M., The Sustainable Development Indicators for Slovenia, 2nd ed., Statistical Office of the Republic of Slovenia: Ljubljana, 49 pp., 2010.

[22] Kauliņš, J., Indicators for sustainable development governance, Summary of the doctoral thesis, University of Latvia, Riga, 36 pp., 2015.

[23] Kovanda, J. \& Hak, T. (ed.), Progress Report on the Czech Republic Sustainable Development Strategy, Government Council for Sustainable Development, Ministry of the Environment, Prague, 186 pp., 2009.

[24] Ernšteins, R., Kauliņš, J., Līce, E. \& Štāls, A., Integrated coastal management for local municipalities in Latvia: sustainability governance and indicator system. WIT Transactions, 149, pp. 29-40, 2011.

[25] Moles, R., Foley, W., Morrissey, J. \& O’Regan, B., Practical appraisal of sustainable development-Methodologies for sustainability measurement at settlement level. Environmental Impact Assessment Review, 28, pp. 144-165, 2008.

[26] Tanguay, G.A., Rajaonson, J., Lefebvre, J.-F. \& Lanoie, P., Measuring the sustainability of cities: An analysis of the use of local indicators. Ecological Indicators, 10, pp. 407-418, 2010. 